\title{
Harran Ovası'nda yaygın bitkilerde sulama performanslarının karşılaştırılması
}

\section{Comparison of irrigation performance of common plants in Harran Plain}

\author{
Yakup KARAASLAN $^{1 *}$ iD Mehmet ŞiMŞEK $^{2}$ iD, Sabri AKIN $^{3}$ iD \\ ${ }^{1}$ Tarım ve Orman Bakanlığı, Su Yönetimi Genel Müdürlüğü, Ankara \\ ${ }^{2}$ Şırnak Üniversitesi, Mühendislik Fakültesi, İnşaat Mühendisliği Bölümü, Şırnak \\ ${ }^{3}$ Harran Üniversitesi, Ziraat Fakültesi, Tarımsal Yapılar ve Sulama Bölümü, Şanlıurfa
}

\section{To cite this article:}

Karaaslan, Y., Şimşek, M. \& Akın, S. (2019). Harran Ovası'nda yaygın bitkilerde sulama performanslarının karşılaştırılması. Harran Tarım ve Gıda Bilimleri Dergisi, 23(4): 432-443.

DOI: 10.29050/harranziraat.556962

\section{Address for Correspondence:} Yakup KARAASLAN

e-mail:

yakup.karaaslan@tarimorman.gov.tr

Received Date:

22.04.2019

Accepted Date:

01.11 .2019
(C) Copyright 2018 by Harran University Faculty of Agriculture. Available online www.dergipark.gov.tr/harranziraat

\section{Öz}

Harran Ovası'nda tam kuraklık trendi gösteren lokasyonda 2016 yılında II.ürün mısır ile ı.ürün pamuk bitkisinde gönüllülük esasını kabul eden üretici parsellerinde sulama performansı çalışılmıştır. Yetiştirme mevsiminde, parsellere uygulanan sulama suyu ve yüzey akışla kaybedilen dönen suların kanallarda hızları muline ile ölçülmüş, ölçülen değerlerden debi, hacim ve derinlik cinsinden hesaplanmıştır. Elde edilen bulgular tarımda aşırı su tüketimlerinin alışkanlık haline geldiğini göstermektedir. Çiftçiler tüm kültür bitkilerinde fazla suyun fazla verim getirdiğine inanmaktadır.

Mısır veya pamuk bitkisinin sulanmasında aşırı su kullanımı ve düşük sulama suyu uygulama randımanın sebepleri sırasıyla; sulama sistemin tamamının açık kanal şebekesi olması, sulama ücret tarifesinde hacimsel uygulama $\left(\mathrm{m}^{3}\right)$ yerine dekar başına (alansal) ücretlendirme uygulaması, gece sulamalarının kontrolsüz kalması, konvansiyonel sulamaların tekniğe uygun gerçekleştirilmemesi, kontrolsüz ve aşırı yoğun ve aşırı sulama uygulamalarına bağlı su kayıpları ve toprak erozyonunun meydana gelmesi gösterilebilir. Elde edilen bulgulardan Harran Ovası'nda sulama randımanı \%34-38 arasında olduğu söylenebilir. Sulama suyu kullanım randımanının (IWUE) düşük olması da bu sebep sonuç ilişkisine bağlanabilir.

Anahtar Kelimeler: Sulama birliği, Mısır, Pamuk, Sulama, Randıman

\section{ABSTRACT}

In 2016, in the location showing a complete drought trend in the Harran Plain, irrigation performances of cotton (first crop) and maize crops (second crop) were studied in the volunteered farmer's parcels. During the growing season, the flow rates of irrigation water and the wastewater on the channels were measured with current meter; and then, flow rate, volume and depth of water were calculated from the measured values. Findings showed that excessive water consumption became a habit in the region. Farmers believe that the excess water results in excess yield.

The reasons for the excessive water consumption and low yield in corn or cotton may be due to open channel network construction; areal irrigation fee tariff instead of volumetric based pricing, uncontrolled night irrigations, conventional irrigation without the desired techniques, the undisciplined wild irrigation and water losses and soil erosion due to excessive irrigation. According to the findings, the irrigation efficiency in Harran Plain is between 34-38\%. Low water use efficiency can also be attributed to the causal relationships described above.

Key Words: Irrigation association, Corn, Cotton, Irrigation, Efficiency 


\section{Giriş}

Tatlı suların kısıtlı olduğu havzalar, küresel su krizi yaşanan bölgelerin ilk sırasında yer almaktadır. Bu havzalarda bitkisel üretimde sulama suyu ihtiyacı kısıtlı su uygulama yöntemleri ile üstün performans yakalanabilir. Bu ve buna benzer tarım yapılan sulama şebekelerinde modern sulama teknikleri ve inovasyon kullanarak sulama randımanlarının artması mümkün olabilir. Düşük sulama performansı gösteren bölgelerin şebekelerinde rehabilitasyon yapılarak basınçlı sulama projeleri uygulamaları ile su kaynağındaki yetersizlik endişesi ortadan kaldırılabilir (Ray ve ark., 2013). Su kullanımında suyun verimliliği ve performansı için sorumluluğu olan önemli sektörler sırasıyla tarım, sanayi ve içme suyu temizlik ve sağlık yer almaktadır. Bunlar içerisinde tarım sektörü en büyük paydaş olup kullanılabilir tatlı su rezervinin yaklaşık \%70'ini kullandığı bilinmektedir. Yerküre üzerinde toplam tarımsal üretim alanlarının $\% 20$ 'sinde sulama yapıldığı ve toplam gıdanın \%40'ı sulu tarım alanlarından karşılandığı bildirilmiştir (Kibona ve ark., 2009; Rosegrant ve ark., 2009; Cassardo ve Jones,2011; Anonymus, 2017). Dünyanın pek çok yerinde yaşanan su sıkıntısı veya kıtlığı bitkisel ve hayvansal üretimler dikkate alındığında her geçen gün biraz daha tatlı suya olan talep artmaktadır. Dünya nüfusu bugün için 7.7 milyar, 2050 yılında 9.6 milyar ve 2100 yılında ise 11 milyar olacağı tahmin edilmektedir (Anonymus, 2019). Yapılan birçok senaryoya göre artan nüfusa paralel olarak gıda ve tarımsal üretime ihtiyaç her geçen gün artacağından dolayı suya olan taleplerin de artacağı ifade edilmektedir (FAO, 2012; Alexandratos ve Bruinsma, 2012). Oysa son yıllarda iklim değişiklerinin büyük salınım göstermesinden dolayı kültür bitkilerinin su taleplerinde ciddi sapmaların yaşanacağına işaret edilmektedir. Bilindiği gibi sulama suyu her zaman dinamik bir yapıya sahiptir. Hidrolojik döngülerde ise suyun akış halinde ki kompozisyonundan yararlanır.

Tarımsal sulamalardaki kayıplar [buharlaşmasızma ve yüzey akış kayıpları] dikkate alınarak net yararlanma hesabı yapılır. Genel olarak konvansiyonel sulamalarda suyun \%50'si veya daha fazlası yüzey akışla veya derine sızma ile kaybedilmektedir. Özellikle yüzey akışla kaybolan suyun yaygın olarak alt kullanıcılar tarafından tekrar kullanılması drenaj sularının kalitesinin uygun olması halinde sıkça başvurulan bir yöntemdir. Kaynaktan alınan sulama suyu bitki tarafından yüzde kaçının yararlanıldığını gösteren çalışmalara sıkça rastlanmaktadır. Tarımsal üretimde nitelik ve niceliğin artırılması suda tasarrufun sağlanması, sulama randımanının temel ilkesidir. Sulama randımanlarının artırılmasında toprakların fiziksel, kimyasal ve biyolojik özellikleri de önemli birer faktördür. Bunlara ek olarak, tarımsal sulamalarda kullanılan suyun miktarını ( $\mathrm{mm}$ ) belirleyen en büyük faktörlerden bir diğeri de iklimdir. Iklime etki eden önemli parametreler sırasıyla; sıcaklık, nispi nem, evaporasyon/buharlaşma, güneş ışınım şiddeti ve benzer parametreler sayılabilir. Fırat Havzası'ndan beslenen ve Atatürk barajından gelen kaynakla sulanan parsellerdeki sulama suları tatlı su (tarımsal+evsel dönen sularla sulanan parsellerdeki sulama sularını) ifade eder. Tatlı sularla sulanan parsellerden yüzey akışla tahliye kanallarına deşarj olan, derin drenajla kollektörlerden çıkarak tahliye kanallarına boşalan suların ve bunlara ilave olarak Şanlıurfa evsel atık sularının da karışımıyla dönen su olarak kullanılması atık su olarak kategorize edilmiştir. Harran Ovası'nda tatlı ve atık su ile sulanan mısır ve pamuk parsellerinden sulamadan sonra alınan toprak numunelerinde tuzlulukla ilgili analizlerde, tuz içeriğinin genelde düşük olduğu

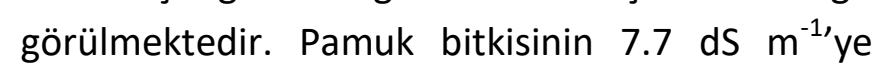
kadar tuza dayanıklı olması (Bernstein, 1955; Katerji ve ark., 2005), tüm sulama dönemlerindeki toprak tuzluluğunun pamuk gelişimi üzerine olumsuz etkisinin bulunmayacağını göstermektedir.

Çalışmada, Harran Ovası'nda mısır ve pamuk denemesindeki tüm sulama dönemlerinde tatlı ve atık su ile sulanan parsellerden alınan toprak numunelerinin elektriksel iletkenlik (EC) değerlerinin, mısır ve pamuk bitkisine hangi düzeyde etkili olacağı araştırılmıştır. 


\section{Materyal ve Metot}

\section{Çalışma alanı ve iklim özellikleri}

Çalışma, Harran Ovası Reha Sulama Birliği sahasında faklı alansal büyüklüğe sahip tatlı suyla sulanan ikinci ürün mısır 47 da ve birinci ürün pamuk 120 da, atıksuyla sulanan ikinci ürün mısır 150 da ve birinci ürün pamuk 47 da olan parsellerde gerçekleştirilmiştir. Tatlı su ise Atatürk Barajından doğrudan hiç kullanılmadan gelen kaynağı ifade eder. Atıksu ise drenaj kanallarından dönen sular ile tarımsal+evsel suların Yardımlı regülatöründe birleştikten sonra, Harran Tahliye Yedek Ana (HYA) kanalına suyun derivasyonu yapılmakta ve bu suyla 10400 ha'lık sahanın sulama suyu ihtiyacı karşılanmaktadır.
Harran Ovası, yazları sıcak ve kurak, kışları ise soğuk ve az yağışlı bir bölgedir. Harran ve Akçakale lokasyonu, 2018-2019 yılı hariç, tam kuraklığa doğru bir eğilim göstermekte olup yıllık yağış $\cong 200 \mathrm{~kg} \mathrm{~m}^{-2^{\prime}}$ dir. Devlet Meteoroloji İşleri Genel Müdürlüğü (DMiGD) Şanlıurfa îli 17270 nolu istasyonuna ait 2016 yılı ve uzun bazı iklim parametreleri Çizelge 1.'de sunulmuştur. Bölgede, haziran, temmuz ve ağustos aylarında en yüksek sıcaklıklar yaşanırken oransal nem temmuz ve haziran aylarında \%25.4 ve \%28.0 olarak ölçülmüştür. Rüzgâr hızı mayıs, haziran ve temmuz aylarında $1.9 \mathrm{~m} \mathrm{~s}^{-1}$ olarak gerçekleşmiştir.

Çizelge 1. Şanlıurfa ilinin uzun yıllar (1960-2016) ve 2016 yılına ait bazı iklim parametreleri (DMGM)

Table 1. Some climate parameters of Şanlıurfa province for long years and 2016 year

\begin{tabular}{|c|c|c|c|c|c|c|c|c|c|c|c|c|}
\hline \multirow{2}{*}{$\begin{array}{l}\text { Parametreler } \\
\text { Parameters }\end{array}$} & \multicolumn{2}{|c|}{$\begin{array}{l}\text { Mayıs } \\
\text { May }\end{array}$} & \multicolumn{2}{|c|}{$\begin{array}{l}\text { Haziran } \\
\text { June }\end{array}$} & \multicolumn{2}{|c|}{$\begin{array}{l}\text { Temmuz } \\
\text { July }\end{array}$} & \multicolumn{2}{|c|}{$\begin{array}{c}\text { Ağustos } \\
\text { August }\end{array}$} & \multicolumn{2}{|c|}{$\begin{array}{c}\text { Eylül } \\
\text { September }\end{array}$} & \multicolumn{2}{|c|}{$\begin{array}{l}\text { Ekim } \\
\text { October }\end{array}$} \\
\hline & $\begin{array}{l}\text { Uz. Yil } \\
\text { Long } \\
\text { Years }\end{array}$ & 2016 & $\begin{array}{l}\text { Uz. Yil } \\
\text { Long } \\
\text { Years }\end{array}$ & 2016 & $\begin{array}{l}\text { Uz. Yıl } \\
\text { Long } \\
\text { Years }\end{array}$ & 2016 & $\begin{array}{l}\text { Uz. Yıl } \\
\text { Long } \\
\text { Years }\end{array}$ & 2016 & $\begin{array}{l}\text { Uz. Yıl } \\
\text { Long } \\
\text { Years }\end{array}$ & 2016 & $\begin{array}{l}\text { Uz. Yıl } \\
\text { Long } \\
\text { Years }\end{array}$ & 2016 \\
\hline $\begin{array}{l}\text { Ortalama sıcaklık }\left({ }^{\circ} \mathrm{C}\right) \\
\text { Average temperature }\left({ }^{\circ} \mathrm{C}\right)\end{array}$ & 22.3 & 23.2 & 28.2 & 29.8 & 31.9 & 33.0 & 31.2 & 33.2 & 26.8 & 26.4 & 20.2 & 22.1 \\
\hline $\begin{array}{l}\text { Ortalama nisbi nem (\%) } \\
\text { Average relative humidity } \\
\text { (\%) }\end{array}$ & 44.9 & 38.3 & 32.8 & 28.0 & 30.1 & 25.4 & 33.1 & 30.6 & 35.8 & 32.1 & 46.4 & 35.9 \\
\hline $\begin{array}{l}\text { Toplam yağış }\left(\mathrm{kg} \mathrm{m}^{-2}\right) \\
\text { Total rainfall }\left(\mathrm{kg} \mathrm{m}^{-2}\right)\end{array}$ & 28.1 & 12.3 & 3.6 & 0.6 & 0.6 & 0.2 & 0.8 & 0.0 & 3.3 & 0.0 & 27.4 & 22.0 \\
\hline $\begin{array}{l}\text { Ortalama buhar basıncı } \\
(\mathrm{mb}) \\
\text { Average steam pressure } \\
(\mathrm{mb})\end{array}$ & 11.9 & 1.0 & 12.5 & 10.9 & 13.9 & 11.8 & 14.3 & 14.3 & 12.3 & 10.4 & 10.6 & 8.7 \\
\hline $\begin{array}{l}\text { Ortalama mahalli basınç } \\
(\mathrm{mb}) \\
\text { Average local pressure }(\mathrm{mb})\end{array}$ & 948 & 947 & 944 & 945 & 940 & 941 & 942 & 944 & 947 & 948 & 952 & 952 \\
\hline $\begin{array}{l}\text { Ortalama rüzgâr hızı }\left(\mathrm{m} \mathrm{s}^{-1}\right) \\
\text { Average wind speed }\left(\mathrm{m} \mathrm{s}^{-1}\right)\end{array}$ & 2.0 & 1.9 & 2.5 & 1.9 & 2.6 & 1.9 & 2.3 & 1.6 & 2.0 & 1.7 & 1.5 & 1.2 \\
\hline
\end{tabular}

Harran Ovası genelinde topoğrafik eğim \%0-2 arasında olduğundan düz ve düze yakın arazilerden oluşmaktadır. Harran isale kanalının doğusunda Tek-Tek dağı platosu, Urfa isale kanalının batısında Fatik platosu eteklerinin bulunduğu, her iki platonun etek eğimleri büyük olduğundan ve sulanabilir arazi kabiliyetlerinin zayıf karakter göstermesinden dolayı, bu sahaların şebeke harici olarak bırakıldığı görülmüştür.

Harran Ovası projesinde; Yukarı Harran, Harran ve Akçakale Yer altı sulamaları (YAS) (toplam $\cong 700$ YAS pompalarıyla) şebekesi dâhil toplam 160000 ha alan sulanmakta olup Ova için sulama

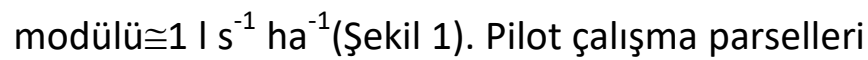
Mülga Reha Sulama Birliği sahasında bulunmakta olup büyüklüğü 10400 ha'dır. 2016 verilerine göre, Sulama Birliği şebekesinin \%85'sinde pamuk \%15'inde mısır ekildiği sulama birliğinin kayıtlarından tespit edilmiştir. 


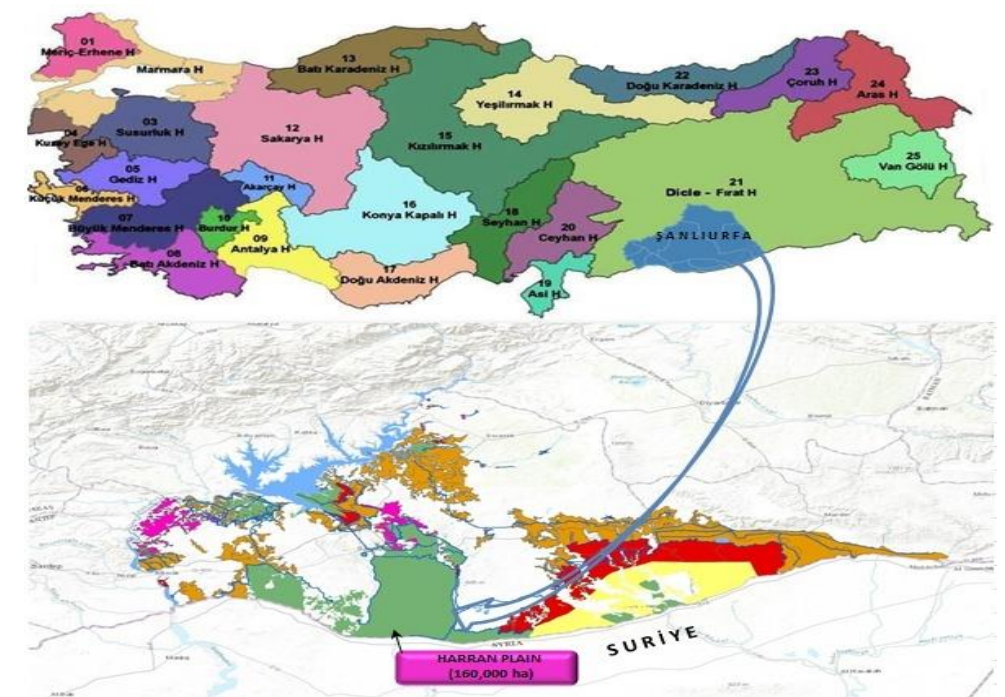

Şekil 1. Dicle ve Fırat havzalarında yer alan Harran Ovası Sulamaları (160000 ha) Figure 1. Harran Plain irrigations (160000 ha) in Tigris and Euphrates River Basins

Harran Ovası toprakları ağır bünyeli killi ve killi tınlı topraklardır. Hidrolik iletkenlikleri beklenenden daha yüksek gerçekleşmiştir. Çalışılan parsellerde sulamalardan önce alınan toprak örneklerinde $\mathrm{pH}$ değeri $8.5^{\prime}$ in altında saptanması, karbonat ve bikarbonat değerlerinin yüksek olmamasından ileri geldiği söylenebilir. Toprakların EC değerinin $7.7 \mathrm{dS} \mathrm{m}^{-1}$ den küçük çıkması, bu alanlarda pamuk yetiştirilebileceğini göstermektedir. Bernstein (1955), Katerji ve ark. (2005), pamuk bitkisi için $7.7 \mathrm{dS} \mathrm{m}^{-1}$ den daha düşük saptanması, kategorik olarak tuza orta şiddette toleranslı bitki grubunda olduğu, EC değerin mısır bitkisinde $4.0 \mathrm{dS} \mathrm{m}^{-1}$ den daha düşük olması gerektiği bildirilmiştir (Çizelge 2).

Çizelge 2. Pilot parsellerde toprakların fiziksel özellikleri

Table 2. Physcial properties of soils in pilot parcels

\begin{tabular}{|c|c|c|c|c|c|c|c|c|}
\hline $\begin{array}{l}\text { Pilot parseller } \\
\text { Pilot Plot }\end{array}$ & $\begin{array}{c}D \\
(\mathrm{~cm})\end{array}$ & $\begin{array}{c}\text { TK } \\
(\% \mathrm{w} / \mathrm{w})\end{array}$ & $\begin{array}{c}\text { SN } \\
(\% w / w)\end{array}$ & $\begin{array}{c}\rho \\
\left(\mathrm{g} \mathrm{cm}^{-3}\right)\end{array}$ & $\begin{array}{c}\text { Kum } \\
\text { Sand } \\
(\%)\end{array}$ & $\begin{array}{c}\text { Kil } \\
\text { Clay } \\
(\%)\end{array}$ & $\begin{array}{l}\text { Silt } \\
\text { Silt } \\
(\%)\end{array}$ & $\begin{array}{l}\text { Bünye Sınıfı } \\
\text { Texture }\end{array}$ \\
\hline \multirow{4}{*}{$\begin{array}{l}\text { Tatlı su } \\
\text { II.ürün mısır } \\
\text { Fresh water } \\
\text { II.Product Corn }\end{array}$} & $0-30$ & 22.30 & 16.66 & 1.48 & 38.16 & 30.56 & 31.28 & KILLİ TIN \\
\hline & $30-60$ & 27.67 & 17.70 & 1.38 & 40.16 & 34.56 & 25.28 & KILLII TIN \\
\hline & $60-90$ & 26.79 & 19.32 & 1.45 & 34.16 & 38.56 & 27.28 & KILLI TIN \\
\hline & $90-120$ & 29.31 & 20.28 & 1.42 & 36.16 & 36.56 & 27.28 & KILLİ TIN \\
\hline \multirow{4}{*}{$\begin{array}{l}\text { Atıksu } \\
\text { II.ürün mısır } \\
\text { Wastewater } \\
\text { II.Product Corn }\end{array}$} & $0-30$ & 24.08 & 19.01 & 1.41 & 34.16 & 34.56 & 31.28 & KILLİ TIN \\
\hline & $30-60$ & 22.60 & 18.60 & 1.39 & 38.16 & 39.56 & 22.28 & KILLI TIN \\
\hline & $60-90$ & 25.33 & 21.97 & 1.31 & 36.16 & 38.56 & 25.28 & KİLI TIN \\
\hline & $90-120$ & 27.95 & 23.28 & 1.44 & 30.16 & 48.56 & 21.28 & KİLLi \\
\hline \multirow{4}{*}{$\begin{array}{l}\text { Tatlı su } \\
\text { I.ürün pamuk } \\
\text { Fresh water } \\
\text { I.product cotton }\end{array}$} & $0-30$ & 21.39 & 17.10 & 1.50 & 34.16 & 30.56 & 35.28 & KÍLLI TIN \\
\hline & $30-60$ & 22.24 & 18.69 & 1.43 & 30.16 & 32.56 & 37.28 & KILLİ TIN \\
\hline & $60-90$ & 21.61 & 17.58 & 1.47 & 36.16 & 30.56 & 33.28 & KIILLI TIN \\
\hline & $90-120$ & 26.72 & 20.07 & 1.41 & 36.16 & 32.56 & 31.28 & KILLI TIN \\
\hline \multirow{4}{*}{$\begin{array}{l}\text { Atıksu } \\
\text { I.ürün pamuk } \\
\text { Wastewater } \\
\text { I.product cotton }\end{array}$} & $0-30$ & 26.76 & 22.13 & 1.36 & 26.16 & 50.56 & 23.28 & KiLLI \\
\hline & $30-60$ & 28.81 & 22.62 & 1.50 & 26.16 & 50.56 & 23.28 & KILLi \\
\hline & $60-90$ & 29.97 & 23.07 & 1.49 & 26.16 & 52.26 & 21.58 & KİLLi \\
\hline & $90-120$ & 34.69 & 25.35 & 1.50 & 26.16 & 52.56 & 23.28 & KILLI \\
\hline
\end{tabular}

TK: Tarla Kapasitesi kuru ağırlık esasına göre (w/w), SN: solma noktası kuru ağılık esasına göre (w/w),

D: derinlik, $\rho$ :hacim ağırlığı

TK: field capacity, SN: permenant wilting point, D: depth, $\rho$ : bulk density 
Mısır ve pamuk bitki varyetesi ve bitki besleme

Çalışma 2016 yılında yapılmış ve at dişi mısır üretimi için Pioneer ve LG mısır çeşidi kullanılmıştır. Tohum ekimi ile birlikte $45 \mathrm{~kg} \mathrm{da}^{-1}$ taban gübresi (20-20-0), temmuz ayının üçüncü haftasında ise, üçüncü sulamadan önce, $45 \mathrm{~kg} \mathrm{da}^{-1}$ \%46 N-üre formunda gübre uygulanmıştır. Mısır tohum ekim tarihleri haziran ayının üçüncü haftasında ve hasat tarihleri ise kasım ayı ortasında gerçekleşmiştir.

Pamuk için bölgede çok yaygın olarak kullanılan Bayer Crop Science Candia ve MAY Stonevilla ST-468 pamuk çeşidi tercih edilmiştir. Çeşidin makineli hasada uygunluğu, uzun elyaf (fibermax) özelliğine sahip olması, her iki çeşidin tekstil piyasasında aranan çeşitler arasına bulunması, misırda ve pamukta tohumluk seçiminde önemli bir faktör olmuştur. Genel olarak tohum (çiğit) ekiminde sıra üzeri $7 \mathrm{~cm}$ kullanılmış ve bitki yoğunluğu $\cong 20000$ adet $\mathrm{da}^{-1}$ hesaplanmıştır. Tohum ekiminden önce tav sulaması yapılmış ve tohum ekimi nisan ayının üçüncü haftasından sonra gerçekleşmiştir. Çiğit ekiminden önce 20-20-0 kompoze taban gübre (\%20 Azot, \%20 P ve \%0 K) $40 \mathrm{~kg} \mathrm{da}^{-1}$, birinci sulama öncesi $25 \mathrm{~kg} \mathrm{da}^{-1}$ üre (\%46 N) ve ikinci sulama öncesi $30 \quad \mathrm{~kg} \quad \mathrm{da}^{-1} \quad \% 33 \quad \mathrm{NH}_{4} \mathrm{NO}_{3}$ uygulanmıştır. Mısır ve pamuk bitkisi hastalık ve zararlıları (Tetranychus cinnabarinus, Bemisia tabaci, Spodoptera littoralis, Septoria pistacina vb.) için farklı pestisitlerle mücadele yapılmıştır. Kütlü pamuk hasadına ekim ayından kasım ayı sonuna kadar devam edilmiştir.

\section{Parsellere alınan suların ölçüm ve \\ değerlendirilmesi}

Deneme parselleri için kanaldan alınan tatlı ve atıksuların, kanaldaki hızları ölçülmüş, ölçülen hızlar kanal alanı ile çarpılarak debiler Eşitlik 1'e göre saptanmıştır (Jarret, 1984; Fox and McDonald, 1985; Kieffer, 1987; Frank, 2006). Saptanan debi değerleri, sulama süreleri ile çarpılarak parsellere uygulanan hacimsel su miktarı hesaplanmıştır (Eşitlik 2).
$Q=A * v$

$V=Q * t$

v: Kanalda akan suyun hızı $\left(\mathrm{m} \mathrm{s}^{-1}\right)$

A: Kanalın kesit alanı $\left(\mathrm{m}^{2}\right)$

$\mathrm{V}$ : Su hacmi $\left(\mathrm{m}^{3}\right)$

$\mathrm{t}$ : Sulama süresi (s)

Parsellerden yüzey akışla deşarj olan suların debileri benzer şekilde ölçülmüş, yedek drenaj kanalların sonlarında yer alan kavşutlarda aynı şekilde debi ve hacimler Eşitlik 1. ve 2'ye göre hesaplanmıştır. Parsellerden derine sızma yoluyla tarla içi drenaj borularından kollektörlere inen sular ise tek bir noktada hacimsel ölçüm tekniğiyle saptanmıştır. Tüm bu yaklaşımlar ve eşitlikler kullanılarak gerek II.ürün mısır ve gerekse pamuk bitkisi su tüketimleri; mevsim başında ve sonunda pilot parsellerde $0-120 \mathrm{~cm}$ derinliğindeki toprak numunelerinin nem içerikleri dikkate alınarak mevsimlik bitki su tüketim değerleri $(\mathrm{mm})$ belirlenmiştir (Eşitlik 3). Önceden Eşitlik 2'ye göre belirlenmiş olan hacimsel suların, parsel alanına (da) bölünerek, pilot parsellere uygulanan sulama suyu derinlikleri ( $\mathrm{mm}$ ) saptanmış ve mevsimlik bitki su tüketimleri (mm) Eşitlik 4'e göre hesaplanmıştır (Allen, 1996).

$E T=I+P+C_{r}-D_{p}+R_{f} \pm \Delta S$

ET: Bitki su tüketimi (mm)

I: Sulama suyu ( $\mathrm{mm})$

P: Etkili yağış $(\mathrm{mm})$.

$C_{r}$ : Kapilar yükselme $(\mathrm{mm})$

$\mathrm{D}_{\mathrm{p}}$ : Derine sızma $(\mathrm{mm})$

$\mathrm{R}_{\mathrm{f}}$ : Yüzey akış kayıpları $(\mathrm{mm})$

$\pm \Delta \mathrm{S}$ : Toprak profilindeki nem değişimi $(\mathrm{mm})$ 'dir.

$d=\frac{V}{A}$

V: Hacimsel su $\left(\mathrm{m}^{3}\right)$

A: Parsel büyüklüğü (da)

$\mathrm{d}$ : Uygulanan suyun derinliği $(\mathrm{mm})$

\section{Pamuk verimi}

Harran Ovası'nda pamuk hasadı, hasat makinesiyle gerçekleştirilmektedir. Çalışmada, pilot parsellerde ortalama parsel verimlerinin saptanması amacıyla kütlü hasadı, her bir pilot 
parselin beş farklı noktasında ve $3.5 \mathrm{~m}^{2 \prime}$ lik alanda elle yapılmış ve laboratuvarda hassas terazide tartımları gerçekleştirilmiştir. Hasat edilen beş farklı noktadaki $3.5 \mathrm{~m}^{2}$ 'lik alandaki kütlü verimleri ortalamaları kullanılmış, arazinin dekara verimleri saptanmıştır. Elyaf verimleri için kütlü pamukta çırçırlama yapılmış ve randımanlar belirlenmiştir.

\section{Bulgular ve Tartışma}

Ova'da, çiftçiler tarafından, genel olarak II.ürün mısır bitkisinde 8-9 sulama uygulanmaktadır. İlk sulamalar haziran ayının son haftasında 7-16 gün arasında değişen aralıklarla, eylül ayının son haftasına kadar devam etmektedir. Suyun kaynağına (tatlı veya atıksuya) bakılmaksızın-Ova daki yaygın sulama tekniği tava sulama şeklinde görülmektedir. Bitkilere uygulanan suyun derinliğine bakıldığında aşırı sulama uygulamaların yapıldığı tespit edilmiştir. Bir dekar arazi için mevsimlik 4-8 saat sulama işçiliği uygulanırken, mevsimlik sulama süresinin bu denli kısa gerçekleşmesinin nedeni, uygulanan suyun debisinin çok yüksek olmasına bağlıdır 4-8 saat da${ }^{1}$ değeri yoğun ve aşırı sulama yapılmasını kanıtlar niteliktedir.

\section{II.Ürün mısırın tatlı ve atık su performansı ve etkileşimi}

Çalışmada, tatlı su ( $47 \mathrm{da}$ ) ile mısır bitkisinde ilk sulamada (I.) $224 \mathrm{~mm}$ (40 saat süreyle ve $73 \mathrm{I} \mathrm{s}^{-1}$ debiyle), son (IX.) sulamada ise $165 \mathrm{~mm}$ (25 saat süreyle ve $86 \mathrm{I} \mathrm{s}^{-1}$ debiyle) su uygulanmıştır. Buna karşın en yüksek suyun uygulandığı VI. Sulamada $367 \mathrm{~mm}$ (36 saat süreyle ve $133 / \mathrm{s}^{-1}$ debiyle) su kullanılmıştır. En düşük uygulanan suyun derinliği son sulamada (165 mm) gerçekleşmiştir. Suyun en fazla uygulandığı VI. Sulamada $87 \mathrm{I} \mathrm{s}^{-1}$ ile en yüksek yüzey akış ölçülmüştür. Deneme parseline giren sulama suyu ile çıkan yüzey akış debisi her sulamada müline yardımıyla sıklıkla ölçülmüş ve ortalama debi $\left(I \mathrm{~s}^{-1}\right)$ değerleri hesaplanmıştır. Derine sızma debileri; kolektörde birim zamanda (saniyede) geçen hacim değerleri (litre) bir kapta (varilde) ölçülmüş ve debi değerleri saptanmıştır. Sulama randımanı en yüksek ilk sulamada \%45.2 ve en düşük beşinci sulamada \%24.7 olarak tayin edilmiştir. Bu çıktılardan anlaşılacağı üzere, bitkinin boyu uzadıkça ve bio-kütlesi hacimsel olarak arttıkça, sulama randımanları ve suyun performansı düşmüştür. Çünkü konvansiyonel sulamalarda, sulama işçisinin parsele girme şansı yani oto-kontrol azalmaktadır. Özellikle ağustos ayının ortasından sonra bio-kütlede maksimum büyüme çanında mod-medyan değerleri elde edilmektedir. Nitekim mısır bitkisinde gerçekleşen dokuz sulamanın kronolojisi, her şeyi özetler gibi görülebilir (Çizelge 3).

Tatlı suyun uygulandığı mısır parselinde yüzey akış suyunun EC değeri $500 \mu \mathrm{Sm}^{-1}$ in altında olup herhangi bir risk oluşturmaz iken, derine sızma ile kollektörlerden çıkan suyun EC değeri $2400 \mu \mathrm{S} \mathrm{cm}$ 1 'nin altında tespit edilmiştir. Derin drenaj kanallarına mansaplanan bu suların alt kotlarda, yukarıdan (membadan) gelen sularla seyreldiği 550-650 $\mu \mathrm{S} \mathrm{cm}{ }^{-1}$ arasında görülmüştür. Drenaj kanallarında seyrelen suların kalite özellikleri bu suların tekrar tarımda kullanılabileceğini göstermiştir.

Çizelge 3. Tatlı su ile sulama yapılan mısırda;yüzey akış $\left(R_{f}\right)$, derine sızma $\left(D_{p}\right)$ ve randıman $\left(E_{n}\right)$

Table 3. In the corn irrigated with fresh water the runoff $\left(R_{f}\right)$, the dee percolation $\left(D_{p}\right)$ and the efficiency $\left(E_{n}\right)$

\begin{tabular}{|c|c|c|c|c|c|c|c|c|c|c|}
\hline $\begin{array}{l}\text { Incelenen parametreler } \\
\text { Examined parameters }\end{array}$ & $\begin{array}{l}\text { I.sul. } \\
\text { I.irr. }\end{array}$ & $\begin{array}{l}\text { II.sul. } \\
\text { Il.irr. }\end{array}$ & $\begin{array}{l}\text { III.sul. } \\
\text { III.irr. }\end{array}$ & $\begin{array}{l}\text { IV.sul. } \\
\text { IV.irr. }\end{array}$ & $\begin{array}{l}\text { V.sul. } \\
\text { V.irr. }\end{array}$ & $\begin{array}{l}\text { VI.sul. } \\
\text { VI.irr. }\end{array}$ & $\begin{array}{l}\text { VII.sul } \\
\text { VII.irr.. }\end{array}$ & $\begin{array}{l}\text { VIII.sul. } \\
\text { VIII.irr. }\end{array}$ & $\begin{array}{l}\text { IX.sul. } \\
\text { IX.irr. }\end{array}$ & $\begin{array}{l}\text { Ort. } \\
\text { Ave. }\end{array}$ \\
\hline Sulama süresi (saat) & 40.0 & 42.0 & 36.0 & 42.0 & 47.0 & 36.0 & 41.0 & 38.0 & 25.0 & - \\
\hline$d\left(\mid s^{-1}\right)$ & 73.0 & 75.0 & 68.5 & 86.0 & 93.0 & 133.0 & 96.0 & 102.0 & 86.0 & - \\
\hline$R_{f}\left(\mid s^{-1}\right)$ & 38.0 & 46.0 & 36.0 & 51.0 & 67.0 & 87.0 & 61.0 & 72.0 & 54.0 & - \\
\hline$D_{p}\left(I s^{-1}\right)$ & 2.0 & 2.0 & 2.0 & 3.0 & 3.0 & 3.0 & 3.0 & 3.0 & 3.0 & - \\
\hline$d_{n}\left(\mid s^{-1}\right)$ & 33.0 & 27.0 & 31.0 & 32.0 & 23.0 & 43.0 & 32.0 & 27.0 & 29.0 & - \\
\hline$E_{n}(\%)$ & 45.2 & 36.0 & 44.5 & 37.2 & 24.7 & 32.3 & 33.3 & 26.5 & 33.7 & 34.8 \\
\hline
\end{tabular}


Mısır bitkisinde 150 dekar için mevsimlik 3.6 saat $\mathrm{da}^{-1}$ sulama işçiliği harcanmış, ilk sulama 23.06.2016, son sulama 16.09.2016 ve hasat ise 23.11.2016 tarihinde gerçekleşmiştir. Sulama suyu derinliği en yüksek $251 \mathrm{~mm}$ (73 saat süreyle ve 143 I s$^{-1}$ debiyle) ile ilk sulamada, en düşük ise143 mm (47 saat süreyle ve $127 \mathrm{I} \mathrm{s}^{-1}$ debiyle) ile sekizinci sulamada uygulanmış. Her iki sulamada yüzey akış sırasıyla $87 \mathrm{I} \mathrm{s}^{-1}$ ve $80 \mathrm{I} \mathrm{s}^{-1}$ ölçülmüş, tüm sulamaların derine sızma kayıpları 4 ve $6 \mathrm{I} \mathrm{s}^{-1}$ arasında değiştiği görülmüştür. Sulama randımanı en yüksek ikinci sulamada \%45.1 ve en düşük yedinci sulamada \%31.0 olarak belirlenmiştir (Çizelge 4). Çalışmanın bu ikinci parselinde de son sulamalara doğru mısır bio-kütlesinin pik gelişimini tamamladığından ve aşırı boylandığından dolayı sulama randımanlarının düştüğü belirlenmiştir.

Çizelge 4. Atıksu ile sulama yapılan mısırda; yüzey akış $\left(R_{f}\right)$, derine sızma $\left(D_{p}\right)$ ve randıman $\left(E_{n}\right)$

Table 4. In the corn irrigated with wastewater; the runoff $\left(R_{f}\right)$, the deep percolation $\left(D_{p}\right)$ and the efficiency $\left(E_{n}\right)$

\begin{tabular}{|c|c|c|c|c|c|c|c|c|c|c|}
\hline $\begin{array}{l}\text { Incelenen } \\
\text { parametreler } \\
\text { Examined } \\
\text { parameters }\end{array}$ & $\begin{array}{l}\text { I.sul. } \\
\text { I.irr. }\end{array}$ & $\begin{array}{l}\text { II.sul. } \\
\text { II.irr. }\end{array}$ & $\begin{array}{l}\text { III.sul. } \\
\text { III.irr. }\end{array}$ & $\begin{array}{l}\text { IV. sul. } \\
\text { IV.irr. }\end{array}$ & $\begin{array}{l}\text { V.sul. } \\
\text { V.irr. }\end{array}$ & $\begin{array}{l}\text { VI.sul. } \\
\text { VI.irr. }\end{array}$ & $\begin{array}{l}\text { VII.sul } \\
\text { VII.irr.. }\end{array}$ & $\begin{array}{l}\text { VIII.sul. } \\
\text { VIII.irr. }\end{array}$ & $\begin{array}{l}\text { IX.sul. } \\
\text { IX.irr. }\end{array}$ & $\begin{array}{l}\text { Ort. } \\
\text { Ave. }\end{array}$ \\
\hline $\begin{array}{l}\text { Sulama süresi } \\
\text { (saat) }\end{array}$ & 73.0 & 71.0 & 77.0 & 67.0 & 54.0 & 44.0 & 55.0 & 47.0 & 48.0 & - \\
\hline$d\left(\mid s^{-1}\right)$ & 143.0 & 133.0 & 127.0 & 124.0 & 132.0 & 143.0 & 116.0 & 127.0 & 125.0 & - \\
\hline$R_{f}\left(I s^{-1}\right)$ & 87.0 & 68.0 & 71.0 & 77.0 & 72.0 & 74.0 & 76.0 & 80.0 & 76.0 & - \\
\hline$D_{p}\left(I s^{-1}\right)$ & 6.0 & 5.0 & 4.0 & 5.0 & 4.0 & 6.0 & 5.0 & 5.0 & 5.0 & - \\
\hline$d_{n}\left(I s^{-1}\right)$ & 50.0 & 60.0 & 52.0 & 42.0 & 56.0 & 63.0 & 36.0 & 46.0 & 40.0 & - \\
\hline$E_{n}(\%)$ & 35.0 & 45.1 & 40.9 & 33.9 & 42.4 & 44.1 & 31.0 & 36.2 & 32.0 & 37.8 \\
\hline
\end{tabular}

Atıksuyun mısır bitkisinde ki sulama suyu, yüzey akış ve derine sızan sularındaki EC değerleri incelendiğinde, sulama sularının $700 \mu \mathrm{S} \mathrm{cm}{ }^{-1}$ nin altında kaldığı görülmüştür. Ancak yüzey akış sularının genel olarak $1000 \mu \mathrm{S} \mathrm{cm}^{-1}$ altında olduğu ve sadece üçüncü sulamada bu değerin yüksek çıkması, üçüncü sulamadan önce uygulanan gübreleme programından kaynaklandığı söylenebilir. Aynı parselin derine sızma değerleri ölçüldüğünde bu kez tüm sulamalarda $6250 \mu \mathrm{S} \mathrm{cm}{ }^{-1}$ altında kaldıkları belirlenmiştir. Yukarıda ifade edildiği gibi $6250 \mu \mathrm{S} \mathrm{cm}^{-1}$ dâhil olmak üzere deşarj olan tüm sular derin drenajda seyreldiğinden dolayı, tarımda tekrar kullanımında bir sınırlamanın bulunmadığı görülmüştür. Harran Ovası'nda çok yaygın olarak kullanılan dönen suların kullanımında mısır veriminde bir düşüş yaşanmamıştır. Her iki tatlı ve atık su ile sulanan parsel verimleri birbirine yakın değerlerde çıkmıştır. Tatlı su ile sulanan mısır, atık suya oranla biraz daha yüksek verim sağlamasının sebebi, atık su ile sulanan parselde tohum ekiminin gerçekleşmesinden kaynaklandığı söylenebilir.
I.Ürün pamuğun tatlı ve atıksu performansı ve etkileşimi

Mülga Sulama Birliği sorumluluk alanında iki farklı parsel büyüklüğünde tatlı ve atık suyun kütlü pamuk verim tepkileri incelenmiştir. Her iki parsel Harran Sol Sahil şebeke sınırlarında olup, sulama suları farklı tipteki kanaletlerden sifonla çekilmiştir.

Pamuk bitkisinin beşinci sulamada gölgelenen alan oranı pik değere yaklaşmış ve yaprak alan indeksi (LAI) maksimum seviyeye ulaşmıştır. Kütlü hasadı ekim ayının ikinci haftasında makine ile gerçekleşmiş, kütlü verimi $550 \mathrm{~kg} \mathrm{da}^{-1,} \mathrm{\prime n}$ biraz üzerinde olduğu ve çırçır randımanı \%45 gerçekleştiği görülmüştür. Tav sulama tohum ekiminden önce nisan ayının ortasında yapılmış ve toplamda yedi sulama gerçekleştirilmiştir. Illk su, tohum ekiminden 49 gün sonra, ardışık sulamalar ise 13-18 gün ara ile uygulanmıştır. Mevsimlik sulama süresi 4.3 saat $\mathrm{da}^{-1}$ olduğu görülmüştür. 120 dekar arazi için ekim öncesi yapılan tav sulamada uygulanan su derinliği 329 mm hesaplanmış, bu sulama için 83 saat sulama süresi 
ve $132 \mathrm{I} \mathrm{s}^{-1}$ debi kanaletten sifonlarla çekilmiştir. Oysa en yüksek sulama suyu birinci sulamada 362 $\mathrm{mm}$ (85 saat sulama süresi ve debi $142 \mathrm{I} \mathrm{s}^{-1}$ ) ve en düşük 280 mm (84 saat sulama süresi ve debi 111 $\left(\mathrm{s}^{-1}\right)$ ile ikinci sulamada ölçülmüştür. Yüzey akışta son sulamada ölçülen en yüksek debi $127 \mathrm{I} \mathrm{s}^{-1}$ iken, en düşük yüzey akışın $64 \mathrm{I} \mathrm{s}^{-1}$ ile ikinci sulamada gerçekleşmiştir. Derine sızma değeri 4-5
${ }^{\prime} \mathrm{s}^{-1}$ arasında değiştiği izlenmiştir. Bir mevsimde tatlı su ile sulanan ve 120 da ölçülen parsele 2196 mm su uygulanırken, bu sudan sadece 753 mm'si bitki tarafından kullanıldığı hesaplanmış, sulamalar tek tek incelendiğinde en yüksek sulama randımanı \%45.3 ile üçüncü sulamada, en düşük randıman \%19.5 ile son sulamada saptanmıştır (Çizelge 5).

Çizelge 5. Tatlı su ile sulama yapılan pamukta; yüzey akış $\left(R_{f}\right)$, derine sızma $\left(D_{p}\right)$ ve randıman $\left(E_{n}\right)$

Table 5.In the cotton irrigated with fresh water the runoff $\left(R_{f}\right)$, the deep percolation $\left(D_{p}\right)$ and the efficiency $\left(E_{n}\right)$

\begin{tabular}{|l|c|c|c|c|c|c|c|c|}
\hline $\begin{array}{l}\text { Incelenen } \\
\text { parametreler } \\
\begin{array}{l}\text { Examined } \\
\text { parameters }\end{array}\end{array}$ & $\begin{array}{c}\text { Tavsul. } \\
\text { Irr. } \\
\text { Befor } \\
\text { sowing }\end{array}$ & $\begin{array}{l}\text { I.sul. } \\
\text { I. irr. }\end{array}$ & $\begin{array}{l}\text { II.sul. } \\
\text { II. irr. }\end{array}$ & $\begin{array}{l}\text { III.sul. } \\
\text { III. irr. }\end{array}$ & $\begin{array}{l}\text { IV. sul. } \\
\text { IV. irr. }\end{array}$ & $\begin{array}{l}\text { V. sul. } \\
\text { V. irr. }\end{array}$ & $\begin{array}{l}\text { VI. sul. } \\
\text { VI. irr. }\end{array}$ & $\begin{array}{l}\text { Ort. } \\
\text { Ave. }\end{array}$ \\
\hline $\begin{array}{l}\text { Sulama süresi } \\
(\mathrm{saat})\end{array}$ & 83.0 & 85.0 & 84.0 & 66.0 & 77.0 & 64.0 & 62.0 & - \\
\hline $\mathrm{d}\left(\mathrm{I} \mathrm{s}^{-1}\right)$ & 132.0 & 142.0 & 111.0 & 148.0 & 146.0 & 151.0 & 164.0 & - \\
\hline $\mathrm{R}_{\mathrm{f}}\left(\mathrm{I} \mathrm{s}^{-1}\right)$ & 81.0 & 94.0 & 64.0 & 77.0 & 86.0 & 98.0 & 127.0 & - \\
\hline $\mathrm{D}_{\mathrm{p}}\left(\mathrm{I} \mathrm{s}^{-1}\right)$ & 4.0 & 5.0 & 4.0 & 4.0 & 4.0 & 4.0 & 5.0 & - \\
\hline $\mathrm{d}_{\mathrm{n}}\left(\mathrm{I} \mathrm{s}^{-1}\right)$ & 47.0 & 43.0 & 43.0 & 67.0 & 56.0 & 49.0 & 32.0 & - \\
\hline $\mathrm{E}_{\mathrm{n}}(\%)$ & 35.6 & 30.3 & 38.7 & 45.3 & 38.4 & 32.5 & 19.5 & 34.3 \\
\hline
\end{tabular}

Sulama şebekesinin ve Harran Ovası'nın en düşük arazi kotunda yer alan parseldir. Bu parselde derine sızan $\left(D_{p}\right)$ sularda en yüksek EC değerleri ölçülmüş, bu değerlerin 10000-17000 $\mu \mathrm{S}$ $\mathrm{cm}^{-1}$ arasında olduğu görülmüştür. Çiğit ekiminden sonra tohumun çimlenmesinde EC değerlerinin yüksek olmasından dolayı, ciddi çimlenme kayıplarının yaşandığı, tohum çıkışından sonra arazide ki bitki yoğunluğu \%10-15 arasında normal bitki yoğunluğuna göre daha düşük olduğu gözlenmiştir. En önemlisi makineli hasatta $440 \mathrm{~kg}$ da ${ }^{-1}$ ile düşük kütlü verimi elde edilmiştir. Gerek tatlı ve gerekse atık sularda çırçır randımanları \%45-\%46 arasında değişmiştir.

Tav sulama dahil toplam yedi sulama gerçekleştirilmiş, ilk sulama ekimden 40 gün sonra, ardışık sulamalar 14-16 gün ara ile ağustos ayının son haftasına kadar devam etmiştir. Hasat ekim ayı başında yapılmış, her dekar arazi için mevsimlik sulama işçiliği 5.0 saat hesaplanmıştır. Uygulanan sulama suyu miktarı en yüksek birinci sulamada $375 \mathrm{~mm}$ (sulama süresi 35 saat ve 140 I $\mathrm{s}^{-1}$ debiyle) ve en düşük beşinci sulamada $176 \mathrm{~mm}$ (sulama süresi 37 saat ve $62 \mathrm{I} \mathrm{s}^{-1}$ debiyle) 47 dekar pamuk parseline uygulanmıştır. En yüksek ve en düşük yüzey akış kayıpları sırasıyla tav sulamada $99 \mathrm{I} \mathrm{s}^{-1}$ ve beşinci sulamada $35 \mid \mathrm{s}^{-1}$ ölçülmüştür. Parsellere uygulanan sulama suları debileri ne kadar fazla olursa, yüzey akış debileri de o kadar fazla deşarj olur. Vahşi sulamaların algoritmasında bu yatmaktadır. Bu nedenle sulamalarda modernizasyon oldukça önemlidir. Nitekim parselin yıllık ortalama sulama randımanı \%35.6 saptanmış, toplam $1804 \mathrm{~mm}$ su uygulanmış ve bitki tarafından kullanılan su $642 \mathrm{~mm}$ hesaplanmıştır (Çizelge 6).

Derine sızan sularda ölçülen EC değerleri 11000-17000 $\mu \mathrm{S} \mathrm{cm}^{-1}$ olması, bu suların sorunlu olduğunun kanıtı sayılabilir. Ancak çıkan suyun 2 I $\mathrm{s}^{-1}$ olması ve isale drenaj kanalında 550-650 $\mu \mathrm{S}$ $\mathrm{cm}^{-1}$ kadar seyrelmesi dikkate alındığında, tahliyeyi oluşturan suların \%90-95'i tarımdan \%5-10'u evsel atık sulardır. Tahliye kanallarında endüstriyel sular bulunmamaktadır. Sonuç olarak suyun kompozisyonu dönen suların sulama suyu olarak kullanabileceğini kanıtlamaktadır. Genel bir değerlendirme yapılacak olursa Harran Ovası'nda tatlı ve atık sularla sulanan bitkilerde, uygulanan 
sulama suyunun EC değerlerinin kritik seviyenin üzerine çıkmadığı, ancak atık suyun yoğun toprak erozyonundan ve askıda katı maddeden dolayı, konvansiyonel sulamaların dışında sulamalarda kullanılamayacağı, çalışmaların bulguları desteklemiştir.

Çizelge 6. Atıksu ile sulama yapılan pamukta; yüzey akış $\left(R_{f}\right)$, derine sızma $\left(D_{p}\right)$ ve randıman $\left(E_{n}\right)$

Table 6. In the cotton irrigated with wastewater the runoff $\left(R_{f}\right)$, the deep percolation $\left(D_{p}\right)$ and the efficiency $\left(E_{n}\right)$

\begin{tabular}{|l|c|c|c|c|c|c|c|c|}
\hline $\begin{array}{l}\text { Incelenen } \\
\text { parametreler } \\
\begin{array}{l}\text { Examined } \\
\text { parameters }\end{array}\end{array}$ & $\begin{array}{c}\text { Tavsul. } \\
\text { irr. } \\
\text { Beforsowin } \\
g\end{array}$ & $\begin{array}{l}\text { I.sul. } \\
\text { I. irr. }\end{array}$ & $\begin{array}{l}\text { II.sul. } \\
\text { II. irr. }\end{array}$ & $\begin{array}{l}\text { III.sul. } \\
\text { III. irr. }\end{array}$ & $\begin{array}{c}\text { IV. sul. } \\
\text { IV. irr }\end{array}$ & $\begin{array}{l}\text { V. sul. } \\
\text { V. irr. }\end{array}$ & $\begin{array}{l}\text { VI. sul. } \\
\text { VI. irr. }\end{array}$ & $\begin{array}{c}\text { Ort. } \\
\text { Ave. }\end{array}$ \\
\hline $\begin{array}{l}\text { Sulama süresi } \\
\text { (saat) }\end{array}$ & 33.0 & 35.0 & 34.0 & 24.0 & 36.0 & 37.0 & 38.0 & - \\
\hline $\mathrm{d}\left(I \mathrm{~s}^{-1}\right)$ & 140.0 & 140.0 & 77.0 & 136.0 & 90.0 & 62.0 & 69.0 & - \\
\hline $\mathrm{R}_{\mathrm{f}}\left(\mathrm{I} \mathrm{s}^{-1}\right)$ & 99.0 & 97.0 & 43.0 & 83.0 & 55.0 & 35.0 & 42.0 & - \\
\hline $\mathrm{D}_{\mathrm{p}}\left(\mathrm{s} \mathrm{s}^{-1}\right)$ & 2.0 & 2.0 & 2.0 & 3.0 & 2.0 & 2.0 & 3.0 & - \\
\hline $\mathrm{d}_{\mathrm{n}}\left(\mathrm{s} \mathrm{s}^{-1}\right)$ & 39.0 & 41.0 & 32.0 & 50.0 & 33.0 & 25.0 & 24.0 & - \\
\hline $\mathrm{E}_{\mathrm{n}}(\%)$ & 27.9 & 29.3 & 41.6 & 36.8 & 36.7 & 40.3 & 36.4 & 35.6 \\
\hline
\end{tabular}

Sulama suyu kullanım randımanı (IWUE) ve su kullanım randımanı (WUE)

Çalışma sonucu elde edilen dane mısır ve kütlü pamuk verimleri için uygulanan sulama suyu miktarları ve mevsimlik su tüketimleri ile aynı mevsimde bitkinin tüketebildiği toprak nemi dikkate alınarak sulama suyu kullanım randımanı (IWUE) ve su kullanım randımanı (WUE) hesaplanmış ve başlıklar halinde aşağıda verilmiştir. II.Ürün mısır için IWUE; tatlı su parselinde $0.492 \mathrm{~kg} \mathrm{~m}^{-3}$, atık su parselinde 0.627 $\mathrm{kg} \mathrm{m}^{-3}$. II.Ürün mısır için WUE; tatlı su konusunda $1.38 \mathrm{~kg} \mathrm{~m}^{-3}$ atık su parselinde $1.36 \mathrm{~kg} \mathrm{~m}^{-3}$. pamuk bitkisinde IWUE; tatlı su için $0.257 \mathrm{~kg} \mathrm{~m}^{-3}$, atıksu için $0.243 \mathrm{~kg} \mathrm{~m}^{-3}$. II.Ürün pamuk bitkisi için WUE; tatlı su parselinde $0.687 \mathrm{~kg} \mathrm{~m}^{-3}$, atık su parselinde $0.554 \mathrm{~kg} \mathrm{~m}^{-3}$ saptanmıştır. Benzer sonuçları Hindistan'da yaşanan kuraklığı minimize, verimi maksimize etmek için pamuk bitkisinde karık (kontrol) ve damla sulamada 2009-2011 yılları arasında çalışılmış, karık sulamada $964 \mathrm{~mm}$, damla sulamada ise günlük $\mathrm{ET}_{\mathrm{c}}$ değerinin 1.0, 0.8 ve 0.6 katsayılarını kullanan konularda sırasıyla; 662, 542 ve $421 \mathrm{~mm}$ su uygulanmıştır. $\mathrm{ET}_{\mathrm{c}}$ için 1.0 katsayısı damla sulama konusundan üç yıl sırasıyla 266.4, 245.0 ve $233.1 \mathrm{~kg} \mathrm{da}^{-1}$ verim elde edilmiş, aynı konu ve yıllar için WUE sırasıyla; 0.342, 0.441 ve $0.404 \mathrm{~kg} \mathrm{~m}^{-3}$ değişmiştir. $\mathrm{ET}_{\mathrm{c}}$ katsayısının 0.6 uygulandığı damla sulama konusunda WUE değerinin $0.359-0.391 \mathrm{~kg} \mathrm{~m}^{-3}$ arasında olduğu bildirilmiştir. Kontrol konusuna göre bu konuda \%30 sulama suyu tasarruf edilmiştir (Rao ve ark., 2016). Bir başka çalışmada benzer sonuçlara ulaşılmış, pamuğa ilk sulama ekimden 28,35 ve 42 gün sonra ve son sulamalar aynı konulara 130, 150 ve 170 gün sonra uygulamışlardır. İlk sulamaların 7 gün arayla gecikmeli verilmesi, yıllara göre değişim göstermiş ve en yüksek WUE ilk yılda ekimden 35 gün sonra ilk sulamanın yapıldığı konuda WUE $0.238 \mathrm{~kg} \mathrm{~m}^{-3}$ ve son sulamanın 150 gün sonra uygulanan konuda 0.236 $\mathrm{kg} \mathrm{m}^{-3}$ hesaplanmıştır (Sandoval-Solis ve ark., 2013). Aşırı ve kontrolsüz karık sulamalarda sulama suyunun evapotranspirasyonu karşılama oranı: pamukta 0.43 iken, aynı eşitlik damla sulamada 1 olarak hesaplanmıştır (Ward ve Pulido-Velazquez, 2008). Bu değer Harran Ovası'nda 0.34-0.38 arasında ve benzer şekilde belirlenmiştir.

Pilot ölçekli yürütülen çalışmada elde edilen bulgular, sulama randımanları düşük seviyede olduğu Merriam ve Keller, 1978; Howell, (2003) tarafından verilen sulama randımanları ile çok az benzerlik bulunduğu anlaşılmıştır. Aynı araştırmacı konvansiyonel sulamalarda \%45-65, fasılalı karıkta \%55-75 arasında bildirilmektedir. Tarla sulama randımanı kademeli karık için \%65, karıktan deşarj olan suların tekrar kullanımında döngülü karık için \%75 öngörülmektedir.

Harran Ovası için bulguların tamamı ve en 
başta sulama randımanları kontrolsüz yapılan aşırı sulamaları tarif etmekte ve çok büyük bir toprak kütlesinin erozyona uğradığı görülmektedir.

Cazibe sulamalarda arazide eğim oldukça önemlidir. Eğimin fazla olduğu yerlerde hızın artacağı toprak-suyu depolama içeriğinin düşeceği bilinir. Modern sulama tekniklerinin kullanımı verimliliği arttıracağından dolayı, özellikle stratejik bitkilerde tercih nedeni sayılabilir. Harran Ovası'nda gerçekleşen sulamalarda benzer durum, Frisvold ve ark., (2018) tarafından bildirilmekte ve sulama randımanlarını toprak bünyesi, arazinin eğimi, parselin büyüklüğü, parselin geometrisi, suyun debisi, yetiştiriciliği yapılan ürünün türü, kalifiye işçi temini, enerji ve yönetim giderleri, mali disiplin ve teknolojik transfer kullanım performansını etkileyen temel yaklaşımlar şeklinde verilmektedir. Özellikle basınçlı sulamalarda randımanlar cazibe sulamalara göre daha yüksek olduğu bilinmektedir.

Sulama yöntemlerinde teknoloji kullanımı sulama randımanları için önem arz eder. Genel olarak sulama zamanına karar aşamasında, çiftçilerin $\% 75^{\prime} i$ bitki fenolojisine bakar ve \%25'i sulama sistemine bağlı kalarak sulama yapar. Arizona çiftçisinin \%15'i sulamaları kontrolsüz ve denetimsiz gerçekleştirir. \%20'si sulama karar aşamasında teknolojiden yararlanır. Uygulanacak suyun derinliğini programla sisteme aktarır. California çiftçisinin \%42'si mevcut sulama sistemlerine güvendiklerini bildirmişlerdir. Arizona ve California çiftçileri sırasıyla; $\% 4^{\prime}$ ü ve $\% 16.8^{\prime} i$ toprak nem sensörü, $\% 0.5$ ve $\% 4.8$ 'i bitki nem içeriği ve \%6.6'sı ile \%11.7'si günlük ET raporlarına bakarak sulamaya karar verir. Bu sonuçlar sulamanın Amerika'da ciddi oranda ve titiz bir şekilde suyunun ekonomik olarak kullanıldığını kanıtlamaktadır (USDA, 2014). Salt teknolojik üstünlüğün olduğu sulamalar \%0 düzeyindedir.

Dünyanın toplam sulanan alanın önümüzdeki 30 yıl içerisinde 242 milyon hektara çıkması beklenmektedir. Nüfusu hızla artan ülkelerin, gıdaya ve doğal kaynaklara olan talepleri de hızla artmaktadır. Oysa çoğu ülkelerde toprak ve su kaynakları son derece sınırlı olması nedeniyle bu ülkelerde ciddi sıkıntılar yaşanılması da kaçınılmazdır (Faurèsa ve ark., 2019). Kaynakların etkin kullanımı için birçok araştırma yapılmakta ve suların verimliliği artırılmaya çalışılmaktadır. İspanya Duero havzasında ülke su kaynaklarının $\% 75$ 'i bulunmaktadır. Bu bölgenin etkin su kullanımının yapılabilmesi için mısır bitkisinde 2014'den 2017'ye kadar dört sulama aralığında WUE değerleri saptanmış, su ihtiyacının sadece \%10'nu doğal yağışlarla, \%90'ı sulama şebekesinden karşılanmış ve bu yıllar arasında 6476-7646 $\mathrm{m}^{3} \mathrm{ha}^{-1}$ su kullanılmıştır (SegoviaCardozo ve ark., 2019).

Kuzey Colorado'da farklı büyüme dönemlerinde mısır bitkisine \%40'lara varan su kısıtları uygulanmış, tozlanma-döllenme ve olgunlaşma dönemlerinde su stresi yaşanmaması durumunda yüksek dane verimleri elde edildiği görülmüştür. Bu nedenle mısır bitkisi özellikle tozlanma-döllenme dönemlerinde su stresini tolere edemeyeceği anlaşılmıştır. Bu ve buna benzer bitkiler tozlanma ve döllenme dönemlerini kuraklık yaşamadan geçirmesi istenmektedir (Comas ve ark., 2019). Yürütülen çalışma ile son derece benzer sonuçlar elde edilmiş, ne var ki Harran Ovası sulamalarında mısır bitkisi tozlanmadöllenme dönemlerinde çeltik sulamalarını andıran şekilde, karık sonları kapatılarak göllendirme yapılmaktadır. Çiftçinin bu yaklaşımı tamamen yanlış yönlendirilmesinden kaynaklanmaktadır.

\section{Sonuç ve Öneriler}

Dünyada suyu tasarruflu kullanmayan ve teknolojik gelişmeleri dikkate almayan ülkelerde su ve toprak için her türlü risk bulunmaktadır. Tarımda mutlaka teknik ve mekanik argümanlar kullanılmalı, zorunlu olması hallerinde nano teknoloji devreye alınmalıdır. Tüm dünya özellikle vahşi sulamalardan en kısa sürede kurtulmalı ve toprak erozyonunun önüne geçilmelidir. Dünyanın hızla artan demografik yapısı için ihtiyacı karşılayacak alternatif yaklaşımlar devreye alınmalı, dönen sular işlem gördükten sonra tekrar tüm sektörlerde kullanılmalıdır.

Sulama performanslarının değerlendirilmesinde; 
iletim randımanı, tarla içi depolama randımanı ve genel sulama randımanı sistemin değerlendirilmesinde önem arz eder. Yüzey sulamalarda konvansiyonel karıkta uygulama randımanı \%45-65, yüzey akışların yeniden kullanımı halinde \%60-80, mikro-yağmurlamada \%85-90, damla sulamada \%85-95 ve gömülü damla sulamalarda \%95'den fazla uygulama randımanı beklenir. Ancak, tarımsal sulamalarda \%100 değerlere asla ulaşılamaz, nedeni hangi tekniği kullanırsanız kullanın sulama yöntemlerine bağlı olarak, su kayıpları da görece olarak artmakta veya azalmaktadır. Tüm yüzey akışlar ve basınçlı sulamalar örnek olarak verilebilir. Sulama sistemleri sulama randımanları ile değerlendirilir. Uniform olmayan sulama uygulamaları su uygulama performansını önemli ölçüde ve negatif yönde etkiler. Parsel içerisinde yoğun su altında kalan bölgelerde bitkide önemli sararmalar görülür ve bu durum verimi düşürür. Aşırı sulamalar yüzey akışla birlikte etkin kök bölgesinde anaerobik koşullar ve bitki besleme materyalinin kök bölgesi altına inmesine neden olduğu bilinir. Genel olarak verimlilik uygun sulama yöntemi ve rejimi ile mümkündür. En önemlisi suyun arazide homojen dağılımı ve suyun ve gübrenin bitki tarafından kolay erişimine bağlıdır.

Dönen suların birden fazla kullanılmasına sınırlama getirilmemesi ve mümkün olduğunca membadan mansaba doğru drenaj kanalları üzerinde basit bağlama yapılarıyla gerek cazibe ve gerekse pompa üniteleri ile sulama şebekelerine kazandırılmasının yararlı olacağı söylenebilir. Fazla suyun fazla verim olmadığı bilinci çiftçi ile görsel ve yazılı basınla paylaşılması halinde sonuç alınabileceği ifade edilebilir. Suyun yüksek performansa erişiminde gece sulamalarının özendirici yaptırımlarla teşvik edilmesi, ilgili idarelerin gece sulamalarını öncelikler arasına alması halinde, mümkün olabilir. Kamu spotu ile fazla suyun fazla verim olmayacağı olgusunun topluma net olarak anlatılması, özellikle mısır bitkisi tozlanma-döllenme dönemlerinde aşırıya varan fazla su kullanımlarından kaçınılmasının yararlı olacağı anlatılabilir. Harran Ovası rehabilitasyon çalışması ile basınçlı sulamalara dönüştürülmesi nihai hedef olmalıdır. Böylece suyun performansı, toprakların tuzlulaşması ve erozyonu çözüme kavuşabilir. Tasarruf yapılacak suyla Güneydoğu Anadolu Projesi (GAP)'nde de yeni sahalar sulamaya açılabilir.

\section{Ekler}

Bu çalışma, T.C. Tarım ve Orman Bakanlığı "Su Yönetimi Genel Müdürlüğü" tarafından desteklenmiştir ve "GAP Bölgesinde Sulamadan Dönen Suların Kontrolü ve Yeniden Kullanımı İçin İyileştirilmesinin Araştırılması" projesinin verilerini içermektedir.

\section{Kaynaklar}

Alexandratos, N., and Bruinsma, J. (2012). World agriculture to wards 2030/2050. The 2012 Revision, ESA Working Paper No. 12-03, Rome: Food and Agriculture Organization of the United Nations.

Allen, R. G. (1996). Assessing integrity of weather data for use in reference evapotranspiration estimation. Journal of Irrigation and Drainage Engineering, 122(2), 97-106.

Anonymus, (2017). Part I global context of fresh water resources chapter 1. Global Water Availability, Distribution and Use Springer International Publishing AG 2017. A. Du Plessis, Fresh water Challenges of South Africa and its Upper Vaal River, Springer Water. DOI 10.1007/978-3-319-49502-6_1

Anonymus, (2019). Accessible on the Web at: http://www.worldometers.info/worldpopulation.11.02.2019

Bernstein, L. (1955). Salt tolerance of field crops-cotton. In 1955 United States Salinity Laboratory Report to Collaborators, Riverside, CA. p. 37-41.

Cassardo, C., Anthony, A., and Jones, J. (2011). Managing Water in a Changing World. Water, 3(4): 618-628. DOI: $10.3390 /$ w3020618

Comas, L. H., Trout, T. J., DeJonge, K. C., Zhang, H., and Gleason, S. M. (2019). Water Productivity under Strategic Growth Stage-Based Deficit Irrigation in Maize. Agricultural Water Management, 212, 433440.

FAO, (2012). Coping with Water Scarcity: An Action Frame work for Agriculture and Food Security. FAO Water Reports 38, Rome: FAO.

FAO, (2014). Irrigation areas, irrigated crops, environment. Date of preparation: December 2014.

Faurèsa, F. M., Hoogeveena, J., and BruinsmabJ, J. (2019). The FAO irrigated area forecast for 2030. Accessible on the Web at:http://apps.fao.org/andAccessible on the Web at: http://www.fao.org/ag/agl/aglw/aquastat/main/ind 
ex.htm 11.02.2019.

Fox, R. W., and McDonald A. T. (1985). Introduction to Fluid Mechanics, 741 pp., John Wiley, New York.

Frank M. W. (2006). Sixth Ed. "Fluid Mechanics", McGrawHill, New York.

Frisvold, G., Sanchez, C., Gollehon, N., Megdal, S. B., and Brown, P. (2018). Evaluating Gravity-Flow Irrigation with Lessons from Yuma, Arizona, USA. Sustainability, 10(5), 1548.

Howell, T. A. (2003). Irrigation Efficiency. Encyclopedia of Water Science, 267-272. DOI: 10.1081/EEWS120010252. Published by Marcel Dekker.

Jarrett, R. D. (1984). Hydraulics of high-gradient streams, J. Hydraul. Eng., 110(11), 1519-1539.

Katerji, N., VanHoorn, J. W., Mastrorilli, M., and Hamdy, A. (2005). Crop sensitivity to salinity. Non-conventional water use: Bari: CIHEAM/EU DG Research, p. 43-51.

Kibona, D., Kidulile, G., and Rwabukambara, F. (2009). Environment, climate warming and water management. Transit Stud Rev., 16, 484-500.

Kieffer, S. W. (1985). The 1983 Hydraulic jump in Crystal Rapid: Implications for river-running and geomorphic evolution in the Grand Canyon. The Journal of Geology, 93(4), 385-406.

Merriam, J. L., and Keller, J. (1978). Farm Irrigation System Evaluation: A Guide for Management. Utah State Univ.: Logan, 271.

Rao, S. S., Tanwar, S. P. S., and Regar, P. L. (2016). Effect of deficit irrigation, phosphorous inoculation and cycocel spray on root growth, seed cotton yield and water productivity of drip irrigated cotton in arid environment. Agricultural Water Management, 169, 14-25.
Ray, D. K., Ramankutty, N., Mueller, N. D., West, P. C., Foley, J. A. (2013). Yield trends are insufficient to double global crop production by 2050. PLOS ONE, 8, 1-8.

Rosegrant, M. W., Ringler, C., Zhu, T. (2009). Water for agriculture: Maintaining food security under growing scarcity. Annual Review of Environment and Resources, 34(1), 205-222.

Sandoval-Solis, S., Orang, M., Richard L. Snyder, R. L., Orloff, S., Williams, K. E., Jenna, M. and, Rodriguez, M. S. J. E. (2013). Spatial Analysis of Application Efficiencies in Irrigation for the State of California Preparedfor: United States Geological Survey and California Institute for Water Resources University of California, Davis. One Shield Ave. Dept. LAWR, Bldg. PES 1111 Davis, CA 95616 This document is available online via World Wide Web at http://watermanagement.ucdavis.edu/e-library/ CA Water Plan Update 2013: Vol 4 Reference Guide, Page 1

Segovia-Cardozo, D. A., Rodríguez-Sinobas, L. and Zubelzu, S. (2019). Water use efficiency of corn among the irrigation districts across the Duero river basin (Spain): Estimation of local crop coefficients by satellite images. Agricultural Water Management, 212, 241-251.

U.S. Department of Agriculture. Farm and Ranch Irrigation Survey, (2013). Volume 3, Special Studies, Part 1 of the 2012 Census of Agriculture, AC-12-SS-1; National Agricultural Statistics Service: Washington, DC, USA, 2014.

Ward, F. A. and Pulido-Velazquez, M. (2008). Water conservation in irrigation can increase water use. Proc. Natl. Acad. Sci. USA, 105(47), 18215-18220. 